\title{
Blunt cardiac injury and intraoperative hypoxaemia
}

A 28-yr-old man sustained blunt chest trauma in a motor vehicle accident. Severe intraoperative hypoxaemia occurred, unresponsive to oxygen and positive expiratory pressure therapy. Trans-oesophageal echocardiography revealed myocardial contusion and tricuspid valve rupture. Dobutamine improved left ventricular function and ejection fraction resulting in an immediate improvement in arterial oxygenation and saturation. Tricuspid injury and the diagnosis of myocardial contusion are discussed. The case highlights the importance of a nonpulmonary mechanism of hypoxaemia.

Un homme de 28 ans a subi un traumatisme thoracique fermé lors d'un accident de la route. $I$ présente une hypoxémie peropératoire grave rebelle à l'oxygénotherérapie et à la ventilation mécanique. Léchocardiographie trans-oesophagienne révèle une contusion myocardique et une rupture de la valve tricuspide. La dobutamine améliore la fonction ventriculaire gauche et la fraction d'éjection avec une amélioration immédiate de l'oxygénation et de la saturation. La lésion tricuspidienne et le diagnostic de contusion myocardique font lobjet de la discussion. Cette observation souligne l'importance des mécanisme non-pulmonaires de lhypoxémie.

Blunt chest trauma may cause life-threatening hypoxaemia by a variety of mechanisms. This report describes a severely traumatized patient whose intraoperative hypoxaemia was correctable when a non-pulmonary component was recognized and treated.

\section{Key words}

COMPLICATIONS: hypoxaemia, tricuspid regurgitation; SURGERY: trauma.

From the Department of Anaesthesia, Sunnybrook Health Science Centre, University of Toronto.

Address correspondence to: Dr. J.H. Devitt, Department of Anaesthesia, C-818, Sunnybrook Health Science Centre, 2075

Bayview Avenue, Toronto, Ontario M4N 3M5.

Accepted for publication March 3, 1993.

\section{Case report}

The patient, a 28-yr-old man, was not wearing a seatbelt when his car collided with the concrete support of a bridge. On arrival at a peripheral hospital he was unconscious and had a left tension pneumothorax and flail chest. Following orotracheal intubation with an $8.0 \mathrm{~mm}$ tracheal tube, placement of a semi-rigid cervical collar, insertion of a left chest tube, and resuscitation with blood and crystalloid, the patient was transferred to Sunnybrook Health Science Centre, a level one trauma centre.

Radiographic investigation disclosed fractures of the odontoid, right maxilla, and ninth thoracic vertebra, and the right hip was dislocated posteriorly. Chest radiography showed a fractured left clavicle, multiple left rib fractures and patchy air space disease at the right base. Computerized tomography (CT) of the head revealed a basal skull fracture and features of shear injury to the brain. The haemoglobin concentration was $143 \mathrm{~g} \cdot \mathrm{L}^{-1}$ and during mechanical ventilation with an inspired oxygen concentration $\left(\mathrm{FIO}_{2}\right)$ of 1.0 arterial blood gases were: pH 7.18, $\mathrm{PCO}_{2} 37 \mathrm{mmHg}, \mathrm{PO}_{2} 82 \mathrm{mmHg}, \mathrm{HCO}_{3} 11$ $\mathrm{mmol} \cdot \mathrm{L}^{-1}$.

Diagnostic peritoneal lavage was positive and the patient was taken to the operating room for laparotomy. Insertion of an intracranial pressure monitoring device and closed reduction of the dislocated hip were also planned. Muscle relaxation was achieved with vecuronium bromide, and anaesthesia was provided with midazolam and intermittent boluses of fentanyl. Findings at laparotomy included capsular tears of both lobes of the liver and a retroperitoneal haematoma.

Intraoperatively the patient's lungs were ventilated with a tidal volume of $750 \mathrm{ml}$, a rate of 20 breaths $\cdot \mathrm{min}^{-1}$, and $\mathrm{FiO}_{2}$ of 1.0. Oxygen saturation by pulse oximetry was 96 to $98 \%$ and end-tidal $\mathrm{PCO}_{2}$ was $16-19 \mathrm{mmHg}$. The abdominal wound was closed without difficulty. At two hours after the induction of anaesthesia and during closure of the abdominal wound, oxygen saturation declined acutely to $79 \%$. At this point the heart rate was 100 and blood pressure $105 / 65 \mathrm{mmHg}$. The patient's lungs were ventilated by hand with $100 \%$ oxygen and pulmonary compliance was judged to be normal. Patency of the endotracheal tube was checked by passage of a suction catheter. No change in airway pressure was noted, and breath sounds were audible bilaterally. Salbutamol, 
eight puffs, was given via the endotracheal tube without effect. A right chest tube was placed urgently, but resulted in no improvement. An intraoperative chest radiograph was unremarkable with exception of the fractured left clavicle and mild bilateral pulmonary contusions. No pneumothorax was seen. Positive end-expiratory pressure (PEEP) $5-10 \mathrm{~cm} \mathrm{H}_{2} \mathrm{O}$ was applied. Blood gas analysis confirmed arterial oxygen desaturation: $\mathrm{pH} 7.26, \mathrm{PCO}_{2}$ $32 \mathrm{mmHg}, \mathrm{PO}_{2} 46 \mathrm{mmHg}, \mathrm{HCO}_{3} 14 \mathrm{mmol} \cdot \mathrm{L}^{-1}\left(\mathrm{O}_{2}\right.$ saturation $74 \%$ ). An intracranial pressure monitoring device was inserted, and the patient was transferred to the intensive care unit $55 \mathrm{~min}$ after the onset of hypoxaemia.

In the ICU, the patient remained hypoxaemic and the clinical findings were unchanged. The extremities were cool and mottled, the heart rate was 125 beats $\cdot \mathrm{min}^{-1}$, blood pressure $98 / 70 \mathrm{mmHg}$, and the neck veins were distended. The physical findings were consistent with the diagnosis of cardiogenic shock. Oxygen saturation was $67-68 \%$ by pulse oximetry on $100 \%$ inspired oxygen and $10 \mathrm{~cm} \mathrm{H}_{2} \mathrm{O}$ of PEEP. Sinus tachycardia and incomplete right bundle branch block were present on the ECG.

A trans-oesophageal echocardiogram (TEE) revealed rupture of the tricuspid valve with free regurgitation. The right atrium and hepatic veins were dilated. The left ventricle was hypokinetic (Grade III-IV) with septal dyskinesis. An air contrast study detected no intracardiac shunt.

After infusion of intravenous dobutamine $5 \mu \mathrm{g}$. $\mathrm{kg}^{-1} \cdot \mathrm{min}^{-1}$, left ventricular function improved markedly as assessed by TEE, oxygen saturation increased to $94-96 \%$, and blood pressure increased to $125 / 85 \mathrm{mmHg}$. There was a marked improvement in the clinical status as assessed by neck vein distension and peripheral perfusion. A flow-directed pulmonary artery catheter was then inserted. Mixed venous $\mathrm{PO}_{2}\left(\mathrm{PV}_{2}\right)$ was $35 \mathrm{mmHg}$, while arterial blood gas analysis revealed: $\mathrm{pH}$ 7.31, $\mathrm{PCO}_{2}$ $34 \mathrm{mmHg}, \mathrm{PO}_{2} 78 \mathrm{mmHg}$. Central venous pressure was $14 \mathrm{mmHg}$, pulmonary artery pressure $23 / 14 \mathrm{mmHg}$, pulmonary capillary wedge pressure was $9 \mathrm{mmHg}$, and cardiac index was $1.6 \mathrm{~L} \cdot \min ^{-1} \cdot \mathrm{m}^{-2}$. Therapy was then directed toward improving cardiac output as judged by mixed venous oxygen saturation.

His postoperative course was complicated by raised intracranial pressure and worsening hypoxia. Seven days after admission the patient deteriorated further. The TEE again demonstrated a flail tricuspid valve with severe regurgitation. It also showed an interatrial septal aneurysm with right to left shunting through a patent foramen ovale, a normal left ventricle and minimally impaired right ventricular function.

The patient was taken to the operating room, and on cardiopulmonary bypass, the tricuspid valve was replaced and the patent foramen ovale was closed. He remained
TABLE Pulmonary causes of hypoxia in trauma patients

Pulmonary contusion

Atelectasis and collapse

Aspiration

Pneumothorax

Pulmonary oedema

Diaphragmatic rupture

comatose postoperatively, however, and brain death was declared by the usual clinical criteria $16 \mathrm{hr}$ after surgery. Death was attributed to raised intracranial pressure and ongoing hypoxaemia.

\section{Discussion}

The sudden occurrence of hypoxaemia during anaesthesia should prompt a rapid evaluation of the patient, breathing circuit and anaesthesia machine, as the patient is manually ventilated with $100 \%$ oxygen. Common causes of hypoxaemia including circuit disconnection, delivery of hypoxic gas mixtures, hypoventilation and endotracheal tube blockage or misplacement, should be quickly detected. In patients who have sustained blunt trauma, several other pulmonary causes of hypoxia should be considered (Table).

Hypoxaemia, after blunt thoracic trauma, when accompanied by hypotension, may indicate cardiac tamponade, tension pneumothorax or hypovolaemia from cardiac, major vessel, or pulmonary injury. Finally, on rare occasions, severe myocardial contusion may result in reduced cardiac output leading to hypoxia.

Diminished oxygen delivery from decreased cardiac output results in lower $\mathrm{P}_{\overline{\mathrm{V}}}$. Any lowering of $\mathrm{P}_{\mathrm{v}} \mathrm{O}_{2}$ will decrease $\mathrm{PaO}_{2}$ in the presence of a shunt. This phenomenon is sometimes overlooked intraoperatively as a cause of hypoxaemia. Considerable shunt must exist for hypoxaemia to occur because even though $\mathrm{P}_{\mathrm{v}} \mathrm{O}_{2}$ may be low, oxygen transfer across the alveolar-capillary membrane is rapid enough to saturate the available haemoglobin.

Our patient had poor myocardial contractility with echocardiographic evidence of myocardial contusion. Disruption of the tricuspid valve caused regurgitation, and further limited cardiac output. The administration of dobutamine was an important resuscitative intervention in this patient. The dramatic improvement in arterial $\mathrm{PO}_{2}$ was achieved by increasing cardiac output, thereby increasing oxygen delivery and hence the $\mathrm{P}_{\mathrm{v}}{ }_{2}$.

Myocardial contusion is a difficult diagnosis to make. Prospective studies of patients with blunt thoracic trauma utilizing radionuclide angiography (RNA) or echocardiography show no correlation with the presence of myocardial injury and elevated CPK assays or ECG ab- 
normalities. ${ }^{1-5}$ While investigations such as RNA and TEE are more sensitive, the significance of a positive finding with regard to dysrhythmias or haemodynamic instability remains questionable. ${ }^{2-4} \mathrm{~A}$ prospective study utilizing continuous holter monitoring and RNA to confirm the presence of myocardial contusion failed to show a correlation between significant dysrhythmias (those requiring treatment) and myocardial injury. ${ }^{2}$ Other studies utilizing RNA and/or echocardiography to confirm the presence of myocardial contusion have also failed to show a correlation between the presence of myocardial injury and haemodynamic instability and death. ${ }^{2-4}$

Traumatic tricuspid valve incompetence is an even rarer entity with fewer than 100 cases reported in the literature. ${ }^{6-9}$ It is usually associated with blunt thoracic trauma causing disruption of papillary muscles, chordae tendinae or valve leaflets, or complete valve destruction. The injury is usually not suspected acutely and patients frequently present with mild symptomatology years after the traumatic event, with typical signs of tricuspid insufficiency and a right ventricular conduction disturbance. ${ }^{6,7}$ There is little recorded experience with surgical treatment in the acute phase, but patients with chronic tricuspid insufficiency generally have had their valves successfully replaced. ${ }^{6,7}$

We report this case to remind those dealing with the anaesthetic management of patients with blunt thoracic trauma that there are causes of intraoperative hypoxia outside the lungs. While the priority is airway management and ventilation in the event of intraoperative hypoxia, once those are ruled out as causes, attention should be turned to the circulatory system.

\section{Acknowledgment}

The authors would like to thank Nancy Huntley for assistance with the preparation of the manuscript.

\section{References}

1 Sutherland GR, Calvin JE, Driedger AA, Holliday RL, Sibbald WJ. Anatomic and cardiopulmonary responses to trauma with associated blunt chest injury. J Trauma 1981; 21; 1-12.

2 McLean RF, Devitt JH, McLellan BA, Dubbin J, Ehrlich $L E$, Dirkson $D$. Significance of myocardial contusion following blunt chest trauma. J Trauma 1992; 33: 240-3.

3 Fenner JE, Knopp R. Lee B, et al. The use of gated radionuclide angiography in the diagnosis of cardiac contusion. Ann Emerg Med 1984; 13: 688-94.

4 Fabian TC, Mangiante EC, Patterson CR, Payne LW, Isaacson ML. Myocardial contusion in blunt trauma: clinical characteristics, means of diagnosis, and implications for patient management. J Trauma 1988; 28: 50-7.

5 Reif J, Justice JL, Olsen WR, Prager RL. Selective moni- toring of patients with suspected blunt cardiac injury. Ann Thorac Surg 1990; 50: 530-3.

6 Gayet C, Pierre B, Delahaye J-P, Champsaur G, AndreFouet $X$, Rueff $P$. Traumatic tricuspid insufficiency - an underdiagnosed disease. Chest 1987; 92: 3: 429-32.

7 Perlroth MG, Hazan E, Lecompte Y, Gougne G. Case report: chronic tricuspid regurgitation and bifascicular block due to blunt chest trauma. Am J Med Sci 1986; 291 : 119-25.

8 Liu S-M, Sako Y, Alexander CS. Traumatic tricuspid insufficiency. Am J Cardiol 1970; 26: 200-4.

9 Rackley CE, Wallace RB, Edwards JE, Katz NM. Tricuspid valve disease. In: Hurst JW (Ed.). The Heart Arteries and Veins, 7th ed., New York: McGraw-Hill, 1990; 855-63. 